\title{
High Heat Flux sensor for infrared thermography determination of heat transfer coefficient of liquid metal cooled target's wall
}

\author{
Jacek A. Patorski *a ${ }^{a}$, Malko Gindrat ${ }^{\mathrm{b}}$ \\ ${ }^{a}$ Accelerator Operation and Development Div., Paul Scherrer Institut, CH-5232 Villigen-PSI, Switzerland \\ ${ }^{\mathrm{b}}$ Process Solutions, Sulzer Metco AG (Switzerland), CH-5610 Wohlen, Switzerland
}

\begin{abstract}
The proton beam passing through the wall area of a liquid metal (LM) target container, called entrance window, is causing deposition of maximum high heat flux amount $140 \mathrm{~W} / \mathrm{cm}^{2}$.

Previous experimental thermo-hydraulics investigations for the MEGAPIE LM-target at the SINQ facility of HeatTransfer-Coefficient (HTC) using InfraRed-Thermography (IRT) have been presented at Thermosense 2006 and 2007 [1], [2] and references therein. During these investigations the IRT active sensors with applied heat fluxes of the small and low range from 2.5 to $15.2 \mathrm{~W} / \mathrm{cm}^{2}$ are used. The heating shell foil of the sensor has been connected to steel dish enclosing LM target container by using electrical insulation ceramic glue. A higher, then achieved $15 \mathrm{~W} / \mathrm{cm}^{2}$, heat flux has lead to delaminating of the heater.

Because of interest to determinate the HTC-chart under real heat flux conditions and investigate some positive effect of heat flux buoyancy on cooling, the idea for the High Heat Flux (HHF) IRT Sensors, using of the Low Pressure Plasma Spraying - Thin Film (LPPS-TF) technology of the Sulzer Metco Company has been created.

The paper presents the idea of multilayer thermal sprayed construction of HHF-IRT-Sensor, few realizations and some results of the first pre-test performed at the PSI LBE Double Pump Loop using the new sensor and the 2DD IRT methodology presented in [1].
\end{abstract}

Keywords: quantitative IR thermography, thermo-hydraulics, plasma spraying coatings, liquid metal coolant, local convection heat transfer coefficient, spallation neutron source, liquid metal target, Acceleration Driven Systems

\section{INTRODUCTION}

In spallation neutron sources a beam of accelerated protons is leading into a target with heavy atomic nuclei for achieving of an "evaporation" of neutrons. Spallation is very effective and easier controlled (then fission) nuclear reaction for a "production" of high intense neutron flux. In the SINQ facility at PSI in Switzerland such neutrons are used for neutron radiography or in different scattering instruments, as "a light" in "neutron microscopy". Another future application are Acceleration Driven Systems (ADS) for proceed of the "burning" of nuclear waste, e.g. burned fuel rods remaining after fission process in Nuclear Power Plants (NPPs), and therefore helping in long-term management of nuclear waste.

One concept for neutron spallation source facility consists from cylindrical vertical steel container with inside circulating heavy liquid metal (LM) target material. The flowing LM is simultaneously used as the target and as the coolant of the steel container hemispherical enclosure wall area, so called the proton beam entrance window [1], [2].

The proton beam, passing through the hemispherical target window, is causing high heat deposition within the wall, e.g. at PSI in SINQ MEGAPIE target for the proton beam of $600 \mathrm{MeV}$ and ca. $1.5 \mathrm{~mm}$ thick steel wall, the "footprint" average heat flux amount $70 \mathrm{~W} / \mathrm{cm}^{2}$ and the maximum of Gaussian distributed heat flux amount of $140 \mathrm{~W} / \mathrm{cm}^{2}$.

The target window has been cooled with forced LM flows. These have a complex "flow in flow" structure: the direct pumped onto the inner window surface jet flow in the main flow, even forced with another own pump (see [2] for details).

Obviously these complex cooling systems flows can be investigated (in an optimal way) by temperature field measurements using InfraRed Thermography (IRT). Our previous experimental thermo-hydraulics investigations of Heat

*jacek.patorski@psi.ch; phone +41 5631020 60; fax +41 5631031 31; http://asq.web.psi.ch/ASQ/projects/liquid/liquid.html

Thermosense XXXI, edited by Douglas D. Burleigh, Ralph B. Dinwiddie, Proc. of SPIE Vol. 7299

$729904 \cdot$ ㅇ 2009 SPIE · CCC code: 0277-786X/09/\$18 · doi: 10.1117/12.818278

Proc. of SPIE Vol. $7299729904-1$ 
Transfer Coefficient (HTC) for the MEGAPIE target have used active heated sensors with low heat flux applied, amount approximately one tenth of real case maximum of $140 \mathrm{~W} / \mathrm{cm}^{2}$. The results in form of HTC-charts have been presented at Thermosense in years 2006 and 2007 [1, 2], where the 2DD IRT methodology, worked out at PSI, have been used.

The diagram in Fig.1 shows PSI experimental results of HTC in central point of window mock-up using old type of glued sensor. The sensor used during measurements presented in [1] has not been designed high heat flux and has failed by delaminating at heat flux q* of ca. $20 \mathrm{~W} / \mathrm{cm}^{2}$. In Fig.1 we can observe the rising of HTC caused by the rising of heat flux buoyancy used on the sensor. In experimentation the Lead Bismuth Eutectic (LBE) has been used as the LM coolant and the PSI LBE Double Pump Loop with flow in flow configuration; main flow Q and by-pass jet flow q, see [1] for details. Already for the small range of low heat fluxes $\mathrm{q}^{*}=2.5-15.2 \mathrm{~W} / \mathrm{cm}^{2}$, the corresponding range of HTC values amount $12^{\prime} 500-15^{\prime} 500 \mathrm{~W} / \mathrm{Km}^{2}$. For the identical LBE cooling conditions (pumped main flow $\mathrm{Q}=1.0 \mathrm{l} / \mathrm{s}$ and by-pass jet flows $\mathrm{q}=0.1-0.2 \mathrm{l} / \mathrm{s}$, the gain in HTC is remarkable and achieved values of ca. $3200 \mathrm{~W} / \mathrm{Km}^{2}$, even though the maximum of heat flux $\mathrm{q}^{*}$ applied by the sensor was only approximately a tenth $\left(15.2 \mathrm{~W} / \mathrm{cm}^{2}\right)$ of awaited real maximum of 140 $\mathrm{W} / \mathrm{cm}^{2}$.

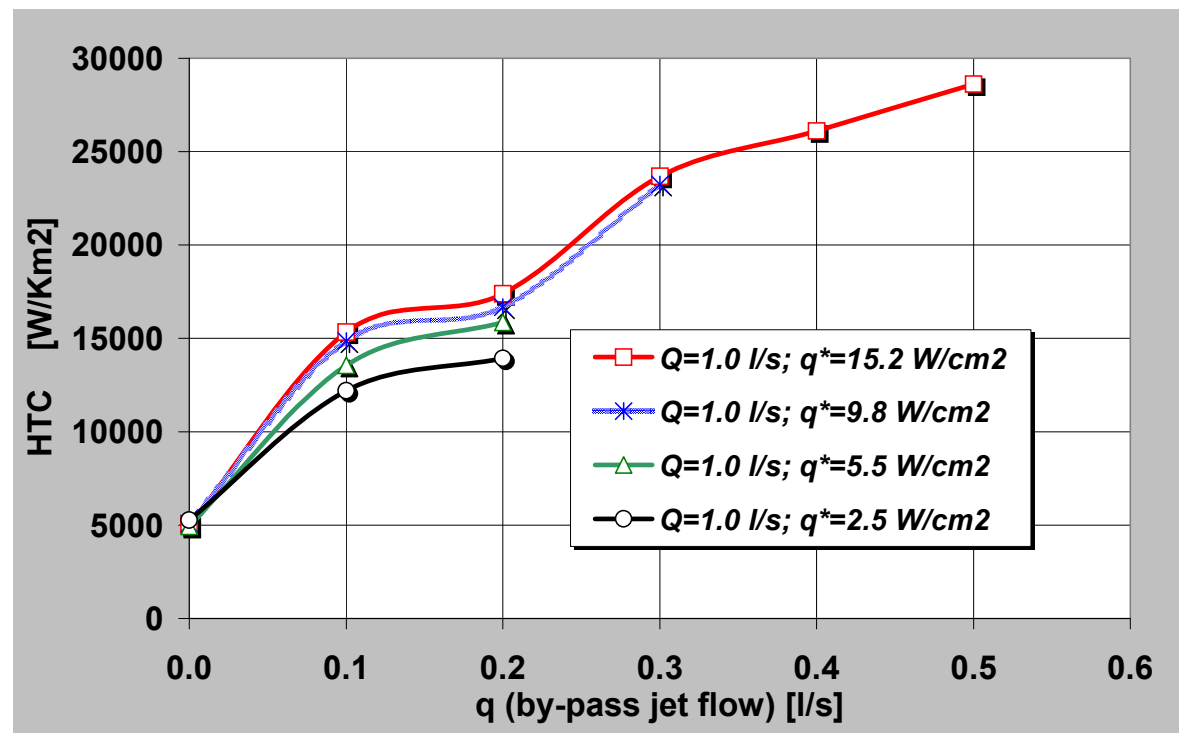

Figure 1: HTC vs. by-pass jet flow $q$ and constant main flow $Q=1.0 \mathrm{l} / \mathrm{s}$ for different heat fluxes (power densities) $q^{*}$ applied by IRT sensor (measured with ca. 10\% accuracy)

The activity for the development of High Heat Flux (HHF) sensors for the measurement of HTC has been proposed because during investigations of an ADS-type MEGAPIE Liquid Metal neutron spallation target's window wall:

- we have not achieved sufficient high heat fluxes allowing a simulation of real target conditions and consequently,

- we can not continue the observation of rising of HTC caused by rising of heat flux through the wall.

For the experimental investigation of HTC at close to the real MEGAPIE conditions and the HTC arising phenomena we need reliable sensors, which will cover a sufficient large range of heat flux applied to the wall. It should be approximately 10 times higher as previous used $15 \mathrm{~W} / \mathrm{cm}^{2}$.

Concluding we are stating that, the responsible for window cooling LM jet flow, which is parallel to the window's wall, is additionally influenced by heat flux buoyancy flow, which is perpendicular to the window's wall. We want to find out the additional conditions accompanying for occurring this phenomena e. g. values of Reynolds number and etc. For this type of LM target window cooling this combination of two motions (pumped jet and high heat flux buoyancy) has taking place and has positive influence on the cooling and should be considered by theoretical/numerical modeling in the full range of heat fluxes occurring in real target. This situation can take a strong influence on velocity, thermal and concentration boundary layers on the window, therefore an adequate theoretical modeling in Computational Fluid Dynamics codes (CFD) has to be created and verified with help of this or other special planned experiments as e.g. COOLWETT Experiment already announced in 2008 [3]. 


\section{CONSTRUCTION IDEA OF PLASMA SPRAYED HHF SENSOR DISH}

The need for the investigations of the cooling in full range of heat flux up to $140 \mathrm{~W} / \mathrm{cm}^{2}$ existing in real MEGAPIE target window lead to the development of new HHF Sensor for IRT measurements.

The idea of the plasma sprayed sensor is based on expectation of good and reliable adhesion between steel substrate and the heater and insulation layers. The simplified schematic of the sensor is presented in Fig.2.

As it was investigated by Michels, Hadeler and Lienhard [4] the small 20x50 mm thermal sprayed heater can produce very high heat fluxes.

For the HHF IRT Sensors several possibilities of thermal spraying have been tested. The most promising method identified at the end was Low Pressure Plasma Spraying - Thin Film (LPPS-TF) technology created and developed by the Sulzer Metco Company from Wohlen in Switzerland

The development at PSI of new HHF sensors for an experimental determination of the local convection HTC, which will simulate the conditions for the proton beam target window, occurred in real ADS-type LM neutron spallation targets, has obtain additional partial supporting from the European Union EURATOM FP6 project VELLA-JRA3.

The main design criterion is the final maximum power density of ca. $140 \mathrm{~W} / \mathrm{cm}^{2}$, which has to be uniformly distributed over the whole heating area of the sensor. Other construction assumptions are: hemispherical cup dish shape, T91 steel as construction material of the target window and using LBE as coolant.

One type of such HHF sensors with homogenously distributed el. resistance heating consist from thin metallic layer directly vacuum plasma sprayed on the outer surface (during the second phase), previously electrical insulated with even plasma sprayed ceramic layer on the outer surface of the sensor dish (during the first phase). The inner surface of this

\section{Design of plasma sprayed HHF sensor dish}
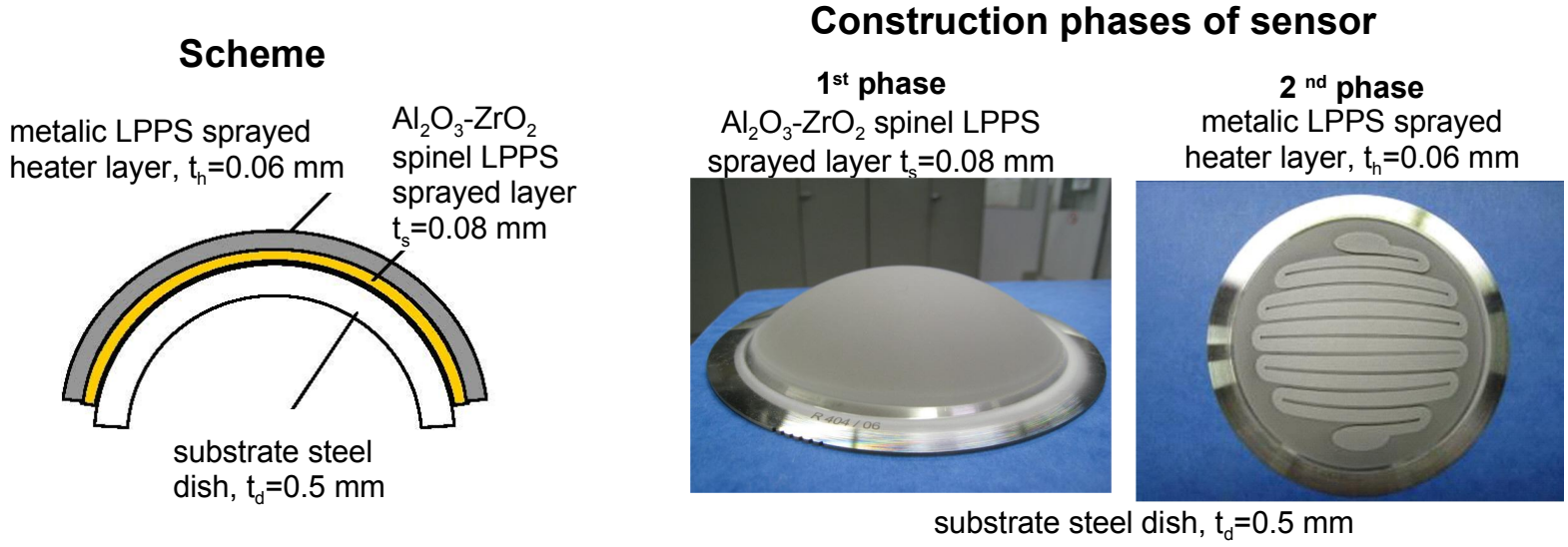

Figure 2. Plasma sprayed type of HHF sensor dish: left, multilayer schematic of sensor dish construction; middle, photos of a sensor with two layers (meander metallic heater layer sprayed on to ceramic electrical insulation layer); right, substrate dish with only electrical insulation ceramic $\mathrm{Al}_{2} \mathrm{O}_{3}-\mathrm{ZrO}_{2}$ spinel layer.

sensor dish is directly contacting the LM-coolant. (See scheme in Fig 2). The flanged sensor cup of the windows dish mock-up can have, on the outer surface, different special shape geometries of heater meanders, which have to be sprayed with special metallic composition FeCrAlY through the mask on to electrical insulation layer of spinel $\mathrm{Al}_{2} \mathrm{O}_{3}-\mathrm{ZrO}_{2}$.

\section{DESIGN REQUIREMENTS / SPECIFICATIONS}

The sensor should fulfill the following base conditions:

a. sensor's active area should cover the concentric round "foot print" area of the proton beam with diameter of $54 \mathrm{~mm}$ but should be not larger than the concentric round "insulation layer" area with a diameter of $106 \mathrm{~mm}$

b. homogenously heat flux of maximum $140 \mathrm{~W} / \mathrm{cm}^{2}$ distributed over the sensor's active area

c. the creation of heat flux should be realized with electric DC resistance heaters with predefined geometries

d. the creation of heat flux over sensor's active area should be independent on the temperature

The first two conditions are leading to the values calculated in Table 1. 
Table 1 Basic design conditions for the sensor

\begin{tabular}{|l|c|c|c|}
\hline Design heat flux & $\mathrm{q}_{\mathrm{d}}$ & 140.0 & $\mathrm{~W} / \mathrm{cm}^{2}$ \\
\hline Proton beam ,foot print“ diameter & $\mathrm{D}_{\mathrm{fp}}$ & 54.0 & $\mathrm{~mm}$ \\
\hline Sensor active heated area maximum & $\mathrm{A}_{\mathrm{m}}=\mathrm{PI}^{*}\left[\left(\mathrm{D}_{\mathrm{fp}}\right)^{2}\right] / 4$ & 91.6 & $\mathrm{~cm}^{2}$ \\
\hline Maximum design power of sensor & $\mathrm{P}_{\mathrm{m}}=\mathrm{q}^{*}{ }_{\mathrm{d}} \cdot \mathrm{A}_{\mathrm{m}}$ & 12825.2 & $\mathrm{~W}$ \\
\hline Maximum diameter of sensor heated area & $\mathrm{D}_{\mathrm{as}}$ & 106.0 & $\mathrm{~mm}$ \\
\hline
\end{tabular}

The third condition in connection with calculated in Table 1 maximum design power of sensor $\mathrm{Pm}=12^{\prime} 825 \mathrm{~W}$ has lead to the choice of a DC power supply which is consists of four units 70V/45A put together in two configurations: configuration "A" $\left(\mathrm{U}_{\mathrm{A}}=280 \mathrm{~V} / \mathrm{I}_{\mathrm{A}}=45 \mathrm{~A}\right)$ and configuration "B" $\left(\mathrm{U}_{\mathrm{B}}=140 \mathrm{~V} / \mathrm{I}_{\mathrm{B}}=90 \mathrm{~A}\right)$ in both cases the maximum of power amount ca.12'600 W what approximately satisfy maximum design power of sensor $\mathrm{P}_{\mathrm{m}}=12^{\prime} 825 \mathrm{~W}$

The further design conditions are strong connected with geometrical shape of sensors heater. Two of few foreseen shapes of 6 and 12 sections meander heaters are shown in Fig.3.

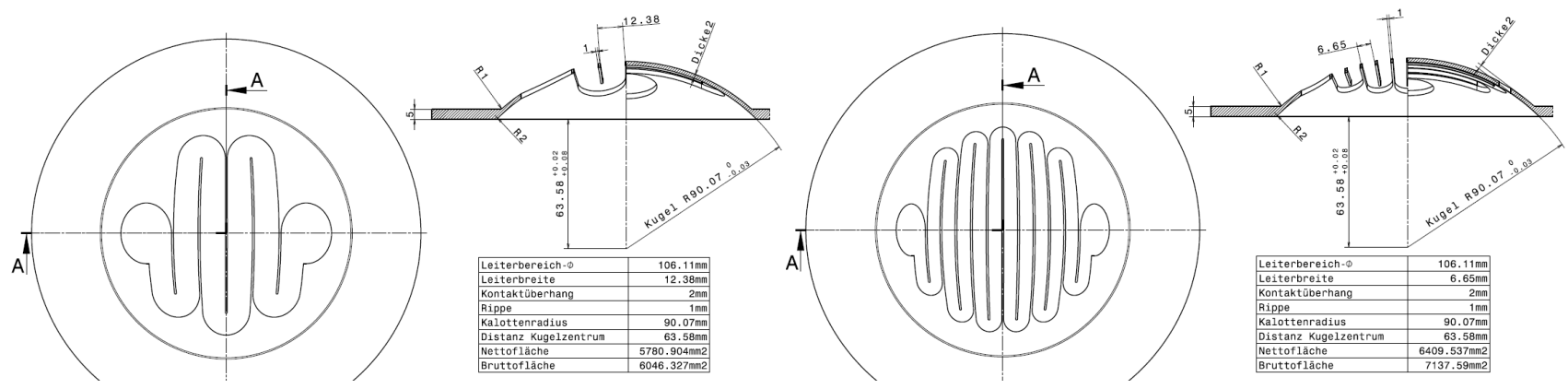

Figure 3. Spraying mask for the 6 and 12 sections meander shape of the heater layer.

The Table 2 summarizes check of sufficiency of the DC power supply and specify needed electrical resistance of heaters, for both configurations "A" and "B" of the DC power supplies, for the design heat flux $\mathrm{q}_{\mathrm{d}}^{*}=140 \mathrm{~W} / \mathrm{cm}^{2}$, and for known geometrical shapes of heaters.

Table 2 Summarizing of design electrical currents and resistance for some chosen sensor's heaters geometries and $\mathrm{q}_{\mathrm{d}}^{*}=140 \mathrm{~W} / \mathrm{cm}^{2}$

\begin{tabular}{|c|c|c|c|c|c|c|}
\hline \multirow[t]{3}{*}{$\begin{array}{l}\text { Sensor's name } \\
\text { (geometry) }\end{array}$} & Area net & Area gross & $\begin{array}{c}\text { Design Power } \\
\text { net }\end{array}$ & $\begin{array}{l}\text { Design Power } \\
\text { gross }\end{array}$ & $\begin{array}{c}\text { Design current } \\
\text { net (power } \\
\text { supply "A") } \\
\text { IAn<45A }\end{array}$ & $\begin{array}{c}\text { Design current } \\
\text { gross (power } \\
\text { supply "A") } \\
\text { IAb<45A }\end{array}$ \\
\hline & $A_{n}$ & $A_{b}$ & $P_{d, n}=q_{d}^{*} \cdot A_{n}$ & $P_{d, b}=q_{d}^{*} \cdot A_{b}$ & $I_{A, n}=P_{d, n} / U_{A}$ & $I_{A, b}=P_{d, b} / U_{A}$ \\
\hline & $\mathrm{mm}^{2}$ & $\mathrm{~mm}^{2}$ & W & $\mathbf{W}$ & A & A \\
\hline $\begin{array}{c}12 \text { sections meander } \\
\text { heater }\end{array}$ & 6410.0 & 7130.0 & 8974.0 & 9982.0 & 32.05 & 35.65 \\
\hline $\begin{array}{c}6 \text { sections meander } \\
\text { heater }\end{array}$ & 5781.0 & 6046.0 & 8093.4 & 8464.4 & 28.91 & 30.23 \\
\hline & $\begin{array}{c}\text { Design current } \\
\text { net (power } \\
\text { supply "B") } \\
I_{\mathrm{B}, \mathrm{n}}<90 \mathrm{~A}\end{array}$ & $\begin{array}{c}\text { Design current } \\
\text { gross (power } \\
\text { supply "B") } \\
I_{\mathrm{B}, \mathrm{n}}<90 \mathrm{~A}\end{array}$ & $\begin{array}{c}\text { Design } \\
\text { el.resistance } \\
\text { net (power } \\
\text { supply "A") } \\
\mathbf{R}_{\mathrm{A}, \mathrm{n}}\end{array}$ & $\begin{array}{c}\text { Design } \\
\text { el.resistance } \\
\text { gross (power } \\
\text { supply "A") } \\
\mathbf{R}_{\mathrm{A}, \mathrm{b}} \\
\end{array}$ & $\begin{array}{c}\text { Design } \\
\text { el.resistance } \\
\text { net (power } \\
\text { supply "B") } \\
\mathbf{R}_{\mathrm{B}, \mathrm{n}}\end{array}$ & $\begin{array}{c}\text { Design } \\
\text { el.resistance } \\
\text { gross (power } \\
\text { supply "B") } \\
R_{B, b}\end{array}$ \\
\hline & $\mathrm{I}_{\mathrm{B}, \mathrm{n}}=\mathrm{P}_{\mathrm{d}, \mathrm{n}} / \mathrm{U}_{\mathrm{B}}$ & $\mathrm{I}_{\mathrm{B}, \mathrm{b}}=\mathrm{P}_{\mathrm{d}, \mathrm{b}} / \mathrm{U}_{\mathrm{B}}$ & $\mathbf{R}_{\mathrm{A}, \mathrm{n}}=\mathrm{U}_{\mathrm{A}} / \mathbf{I}_{\mathrm{A}, \mathrm{n}}$ & $\mathbf{R}_{\mathrm{A}, \mathrm{b}}=\mathbf{U}_{\mathrm{A}} / \mathbf{l}_{\mathrm{A}, \mathrm{b}}$ & $\mathrm{R}_{\mathrm{B}, \mathrm{n}}=\mathrm{U}_{\mathrm{B}} / \mathrm{I}_{\mathrm{B}, \mathrm{n}}$ & $\mathbf{R}_{\mathrm{B}, \mathrm{b}}=\mathrm{UB} / \mathrm{I}_{\mathrm{B}, \mathrm{b}}$ \\
\hline & A & A & $\mathbf{\Omega}$ & $\mathbf{\Omega}$ & $\mathbf{\Omega}$ & $\mathbf{\Omega}$ \\
\hline $\begin{array}{c}12 \text { sections meander } \\
\text { heater }\end{array}$ & 64.10 & 71.30 & 8.74 & 7.85 & 2.18 & 1.96 \\
\hline $\begin{array}{l}6 \text { sections meander } \\
\text { heater }\end{array}$ & 57.81 & 60.46 & 9.69 & 9.26 & 2.42 & 2.32 \\
\hline
\end{tabular}




\section{THE LPPS-TF TECHNOLOGY FOR THE PRODUCTION OF HHF SENSOR DISHES}

Fig. 4 shows the schematic of vacuum chamber and main characteristic of system process description and Fig. 5 shows the schematic of special movement shape used for more density of sprayed layers. The very complex and sensitive LPPS and LPPS Thin Film (TF) technology beside huge experience and specialist knowledge (in average from 10 to 20 parameters can influence the final result of process [5], the very common is using the "tray and go" procedure. It is the case in our project. After many trials we have obtain the good quality of the spraying layer have tested with acceptable results and now we are going to present our application to the international audience.

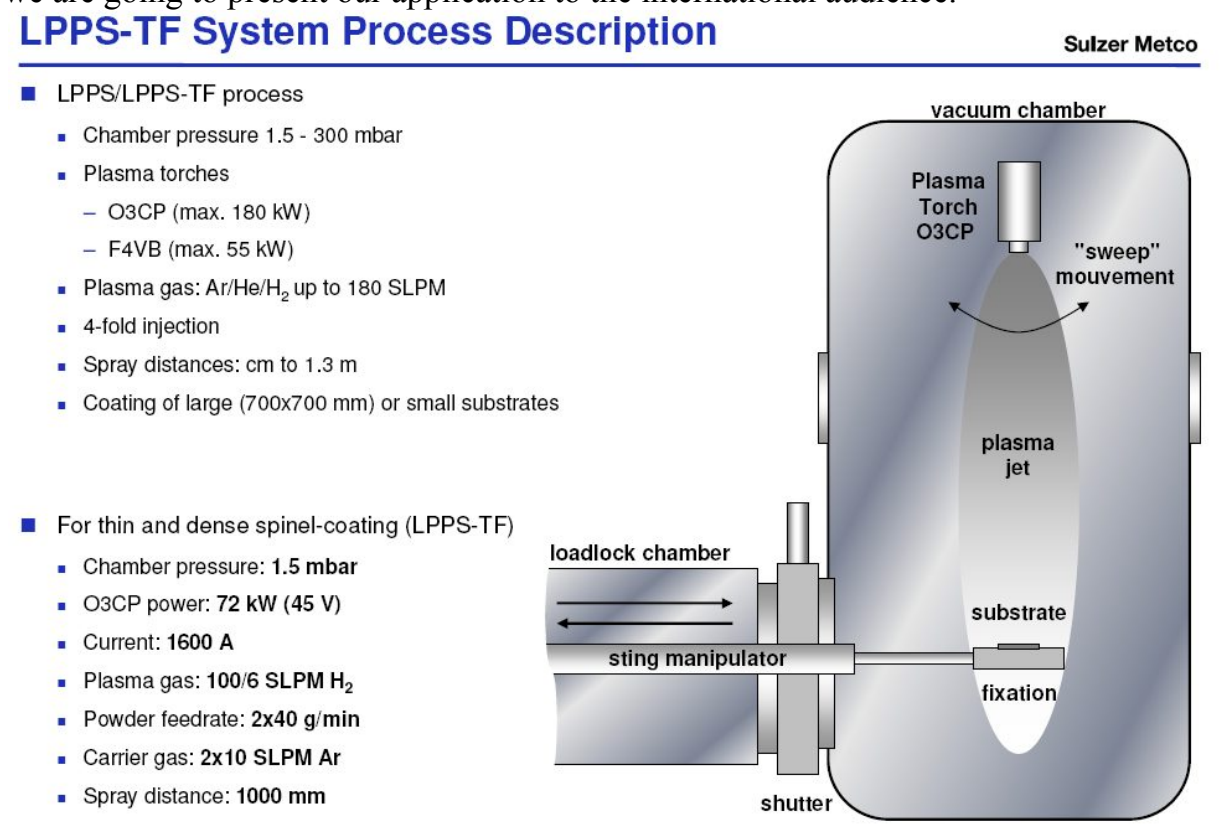

Figure 4. Short description and schematic of Sulzer Metco LPPS System

- To obtain the best homogenous coating on the substrate, 1 type of gun movement was used. The W shape movement improves the homogeneity of the coating and temperature distribution on the surface. Here an example of the movement:
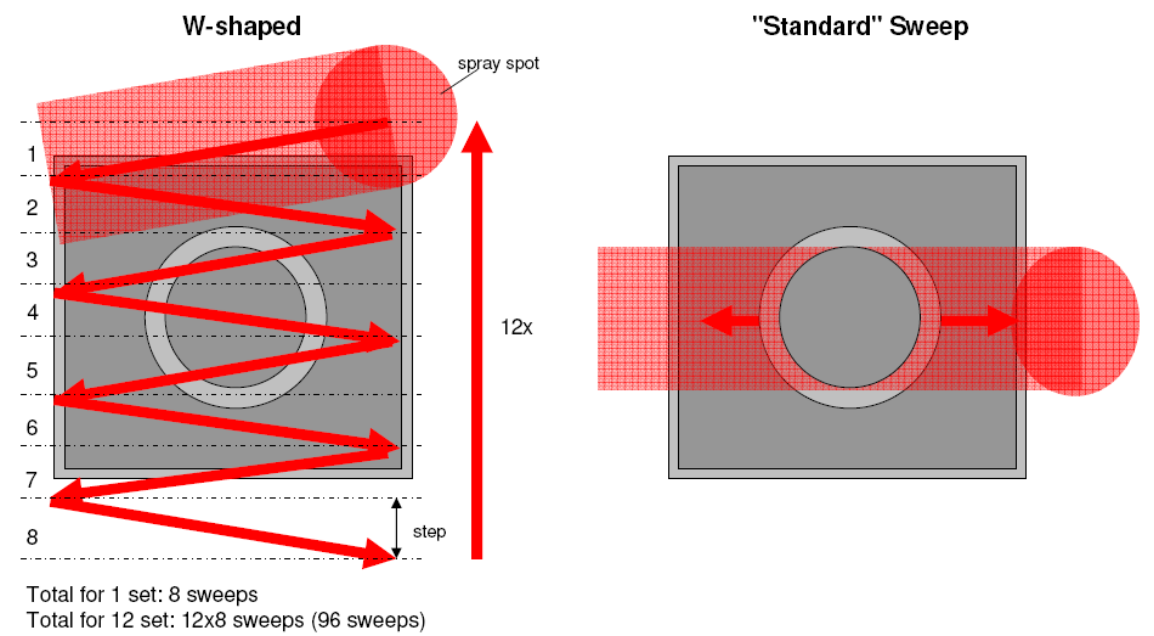

Figure 5. Used "W"-Shape of the plasma gun movement of Sulzer Metco LPPS System 


\section{REALISED PROGRAMME OF LPPS-TF WORKS FOR HHF SENSOR DISHES}

The LPPS-TF Sulzer facility has been used for producing of two chemical different layers. The function of the first ceramic spinel layer which is directly sprayed on to outer steel surface of the sensor dish is, the electrical insulation for the second metallic layer. The function of this second layer is to create the electrical resistance heater.

Table 3. Summary of sprayed layers for metallic sprayed sensor dishes R404/01-05

Summary of spraying Phase \#2 with steel FeCrAlY resistance heater sprayed on sensors dishes R404/01-05

Coating Program for different geometries, thick 28 and 60 microns of steel on ceramic on T91 steel dishes

\begin{tabular}{|c|c|c|c|c|c|c|c|c|c|c|c|c|c|c|c|}
\hline samples & & \multicolumn{3}{|c|}{ plasma parameter } & \multirow[b]{2}{*}{ type } & \multirow{2}{*}{$\begin{array}{l}\text { powder } \\
\text { feed rate }\end{array}$} & \multirow[b]{2}{*}{ carrier gas } & \multicolumn{2}{|c|}{ gun movements } & \multicolumn{2}{|c|}{ plasma power } & \multirow[b]{2}{*}{$\begin{array}{c}\text { coating } \\
\text { time }\end{array}$} & \multirow[b]{2}{*}{ weight } & \multirow{2}{*}{\begin{tabular}{|l|} 
operator \\
thickness \\
\end{tabular}} & \multirow[b]{2}{*}{ heater } \\
\hline type & Arflow & Heflow & H2flow & current & & & & sweep & standoff & voltage & power & & & & \\
\hline & SLPM & SLPIM & SLPM & $A$ & & $\mathrm{~g} / \mathrm{min}$ & SLPIM & \# & $\mathrm{mm}$ & V & $\mathrm{kW}$ & mm:ss & $\mathrm{g}$ & $\mathrm{mm}$ & Ohm \\
\hline Dish R404/01 & 65 & - & 4 & 1600 & $F 4351$ & $2 \times 40$ & $2 \times 5$ & $8 \times 10$ & 1000 & 38.4 & 61.44 & $01: 10$ & 1.6 & 60 & 11.5 \\
\hline Dish R404/02 & 65 & - & 4 & 1600 & F4351 & $2 \times 40$ & $2 \times 5$ & $8 \times 10$ & 1000 & - & - & 01:05 & 0.8 & 28 & 25.9 \\
\hline Dish R404/03 & 65 & - & 4 & 1600 & F4351 & $2 \times 40$ & $2 \times 5$ & $4 \times 10$ & 1000 & - & - & $01: 05$ & 0.9 & 29 & 25.1 \\
\hline Dish R404/04 & 65 & - & 4 & 1600 & F4351 & $2 \times 40$ & $2 \times 5$ & $4 \times 10$ & 1000 & - & - & $01: 05$ & & & 3.2 \\
\hline Dish R404/05 & 65 & - & 4 & 1400 & F4351 & $2 \times 40$ & $2 \times 5$ & $4 \times 10$ & 1000 & - & - & $01: 05$ & & & 32.8 \\
\hline
\end{tabular}

Summary of spraying Phase \#1 with spinel Al2O3 + ZrO2 ceramic insulation on sensor dishes R404/01-05 Coating Program for $60-80$ microns of ceramic on T91 steel dishes

\begin{tabular}{|c|c|c|c|c|c|c|c|c|c|c|c|c|c|c|c|}
\hline samples & \multicolumn{3}{|c|}{ plasma parameter } & \multirow[b]{2}{*}{ current } & \multirow[b]{2}{*}{ type } & \multirow{2}{*}{$\begin{array}{l}\text { powder } \\
\text { feed rate }\end{array}$} & \multirow[b]{2}{*}{ carrier gas } & \multicolumn{2}{|c|}{ gun movements } & \multicolumn{3}{|c|}{ plasma power } & \multirow{2}{*}{\begin{tabular}{|l|} 
operator \\
weight \\
\end{tabular}} & \multirow{2}{*}{ thickness } & \multirow[b]{2}{*}{$\begin{array}{c}\mathbf{n} \\
\text { resistanc }\end{array}$} \\
\hline type & Arflow & Heflow & H2flow & & & & & sweep & standoff & voltage & power & $\begin{array}{c}\text { coating } \\
\text { time }\end{array}$ & & & \\
\hline & SLPIM & SLPIM & SLPIM & $A$ & & $\mathrm{~g} / \mathrm{min}$ & SLPM & \# & $\mathrm{mm}$ & $V^{2}$ & $\mathrm{~kW}$ & $\mathrm{~mm}: \mathrm{ss}$ & $\mathrm{g}$ & $\mathrm{mm}$ & MOhm \\
\hline Dish R404/01 & 100 & - & 6 & 1600 & F6009 & $2 \times 40$ & $2 \times 10$ & $20 \times 10$ & 1200 & 44.3 & 70.9 & $02: 10$ & 2 & 78 & 4.3 \\
\hline Dish R404/02 & 100 & - & 6 & 1600 & F6009 & $2 \times 40$ & $2 \times 10$ & $20 \times 10$ & 1200 & - & - & - & 2.6 & 62 & 3.3 \\
\hline Dish R404/03 & 100 & - & 6 & 1600 & F6009 & $2 \times 40$ & $2 \times 10$ & $20 \times 10$ & 1200 & - & - & - & 2.1 & 70 & 6.0 \\
\hline Dish R404/04 & 100 & - & 6 & 1600 & F6009 & $2 \times 40$ & $2 \times 10$ & $20 \times 10$ & 1200 & - & - & - & 2 & 65 & 7.2 \\
\hline Dish R404/05 & 100 & - & 6 & 1600 & F6009 & $2 \times 40$ & $2 \times 10$ & $20 \times 10$ & 1200 & - & - & - & 2.1 & 56 & 60.0 \\
\hline
\end{tabular}

We have done 5 runs with spinel coating and top metallic coating using different masks and LPPS-TF parameters (different circuit shapes will give different heating / electrical resistance properties). Table 3 presents all important parameters of LPPS technology as: plasma gas, current and power, powder data, gun movements, Fig. 6 shows all five HHF Sensors dishes. The sensor dish R404-03 had no resistance to the mass i.e. is short-circuited and could not be used. Other dishes have sufficient resistance to the mass amount 1 to $3 \mathrm{M} \Omega$ by voltage of $250 \mathrm{~V}$. For the further test only two dishes with lower sensor heater resistance R404-04 >3.1 $\Omega$ and R404-01 >11.3 $\Omega$ have been chosen and for calibrations goals will be additionally instrumented with two resp. three thermocouples on the inner surface of the sensor dish.
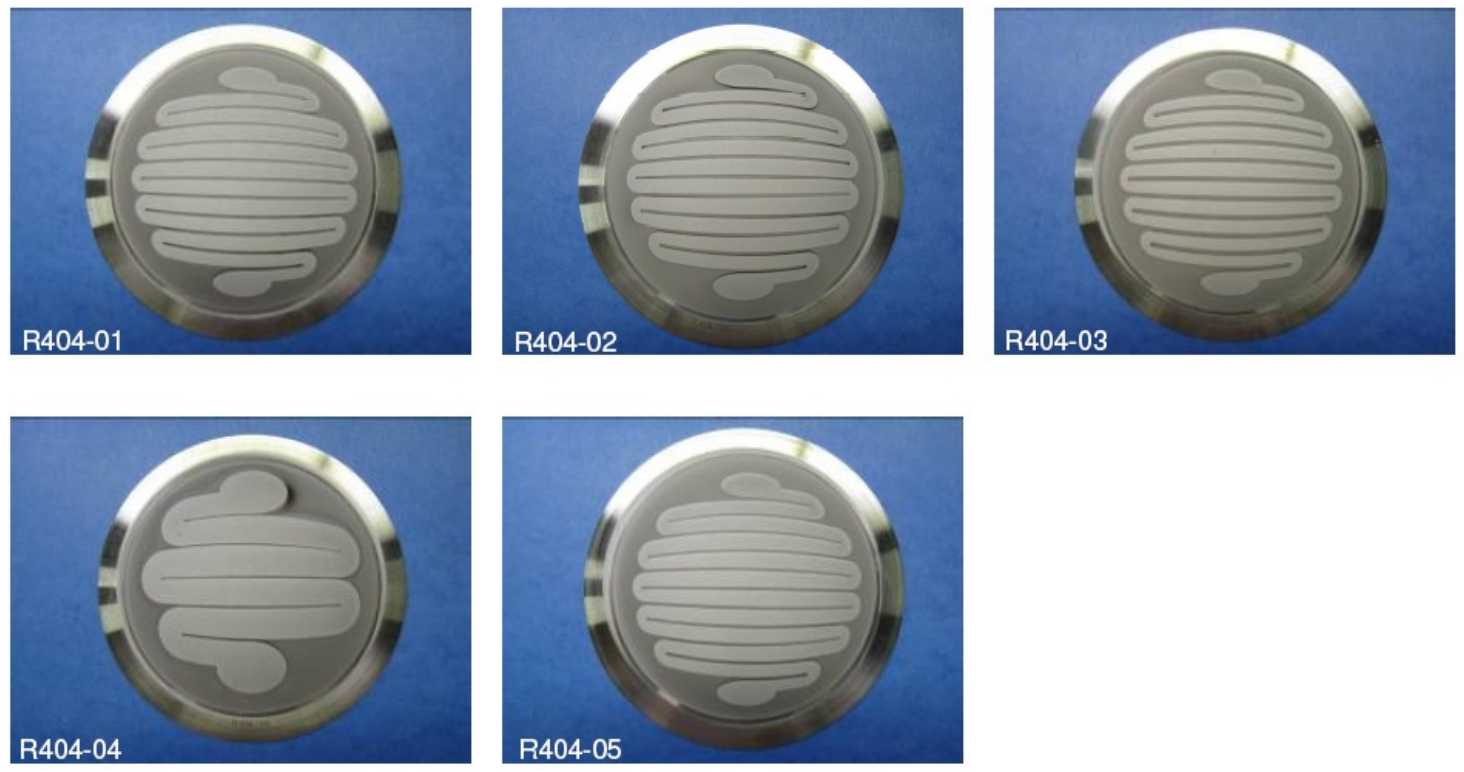

Figure 6. All Type 2 HHF metallic sprayed sensor dishes and el. resistances of sensor heaters:

R404-01 >11.3 $\Omega, \mathrm{R} 404-02 \sim>25.9 \Omega, \mathrm{R} 404-03 \sim>24.8 \Omega, \mathrm{R} 404-04 \sim>3.1 \Omega, \mathrm{R} 404-05 \sim>32.5 \Omega$ 


\section{EXPERIMENTATION: PSI-TESTS ON PLASMA SPRAYED HHF SENSORS}

The first series the PSI-Tests using the Dish \#4 and \#1 from whole set of plasma sprayed dishes, as shown in Fig.6, have been performed at PSI using LBE Double Pump Loop facility.

\subsection{Goals of PSI-Tests}

The main goal of at PSI performed Tests is verification of the basic construction idea of the HHF sensor before the full flow-load matrix experiments at KALLA loop in Karlsruhe in Germany, which will be organized at the end phase of VELLA-JRA3-project (planned in May 2009)

Particularly during the Tests at PSI have the following goals:

- Checking the quality and the stability of adhesion between the layers and steel substrate at the foreseen load limits.

- Fulfilling of design parameters especially the maximum heat flux

- Measurement of electrical resistance of senor heaters layers, within the LBE Target working temperature range from $170^{\circ} \mathrm{C}$ to $400^{\circ} \mathrm{C}$

- Determination of electrical resistivity of plasma sprayed metallic layers for better designing of further sensors

- Observing the behaviour of the electrical contacts of the DC power supply wires leading current into the sensor heater.

- Preliminary determination of HTC values.

\subsection{Matrices of PSI-Tests}

Table 4. Matrices of electrical load used for HHF Sensor Dish \#04 and Dish \#01

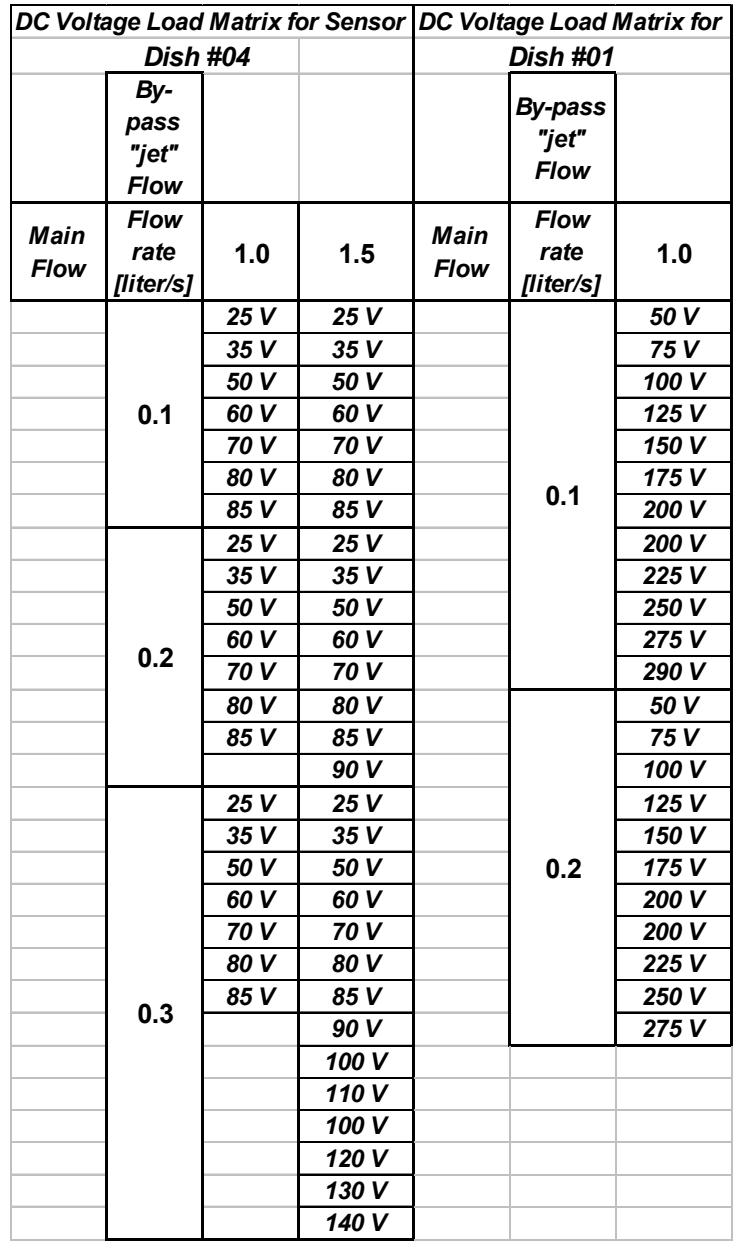

Two series of IRT measurement load cases for two HHF Sensor Dishes have been performed. The first \#04 with low resistance (see Table 3) according design calculation (see Tab.2) has been connected to the power supply configuration "B". The second sensor \#01 has higher resistance and according Tab.2 and Tab3. has been connected to the power supply configuration „A". Table 4 shows the two matrices of DC voltage load applied to the sensors heaters

\subsection{Instrumentation and experimental set-up of Pre-Tests}

According our to experience on the determination of HTCcharts [1],[2] the HHF Sensor Dishes have to be scanned with IRT equipment and additionally they have to be instrumented with very fine thermocouples (TC) Type K with outer sheet diameter of $0.25 \mathrm{~mm}$ and very short time constant.

Fig. 7 shows two photos: the first photography shows of the dish \#4 flanged to the test section, and second photography shows the insertions of lower part of the target before mounting of the outer enclosure-container; central riser pipe (RP) and by-pass jet nozzle (NBP). Fig. 8 shows the test section, which is representing lower part of the target. The reference geometrical LBE flow conditions of well known MEGAPIE LM target have been used. The entire set-up with all the instrumentation of the IRT based experiment is shown in Fig. 8. The so-called "three flanged mock-up" of the lower part of the MEGAPIE target has been fabricated from stainless steel. The upper flange represents an interface to the THEADES loop of the KALLA laboratory at Karlsruhe Institut of Technology KIT in Germany or an interface to the circuits PSI-LBE double pump loop. The second middle flange represents the interface to the so-called "vacuum chamber", a device for realization of adiabatic boundary conditions for the IRT measured sensor dish. 


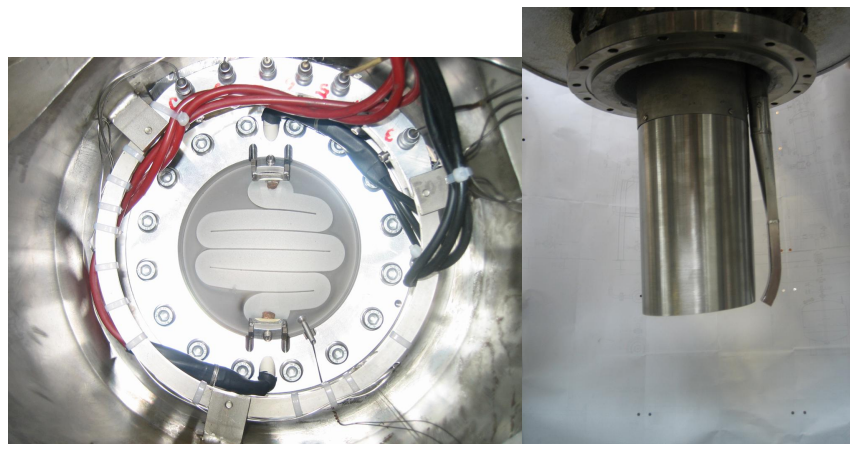

Figure 7. View on the mounted HHF sensor dish \#4 through vacuum chamber and view of the MEGAPIE-type riser pipe (RP) and bypass jet nozzle (NBP)
Controlling the surrounding ambient temperature reduces the radiation loss. And finally, a third small lower flange is fixing the HHF Sensor Dish the simulator of heat flux deposition on the target window. The IRT scanner FLIR-AGEMA Thermovision 900 will measure the temperature field of the specimen from the distance of approx. $1000 \mathrm{~mm}$ through the calcium fluoride crystal glass at the lowest part of the vacuum chamber. For safety reasons the IRT scanner is placed perpendicular to the target axis and take measurement from the reflected heat radiation in high quality polished aluminum IR mirror. It is necessary to save the expensive IRT scanner in the hypothetical accident case of the break of both the specimen sensor dish and calcium fluoride IR window.

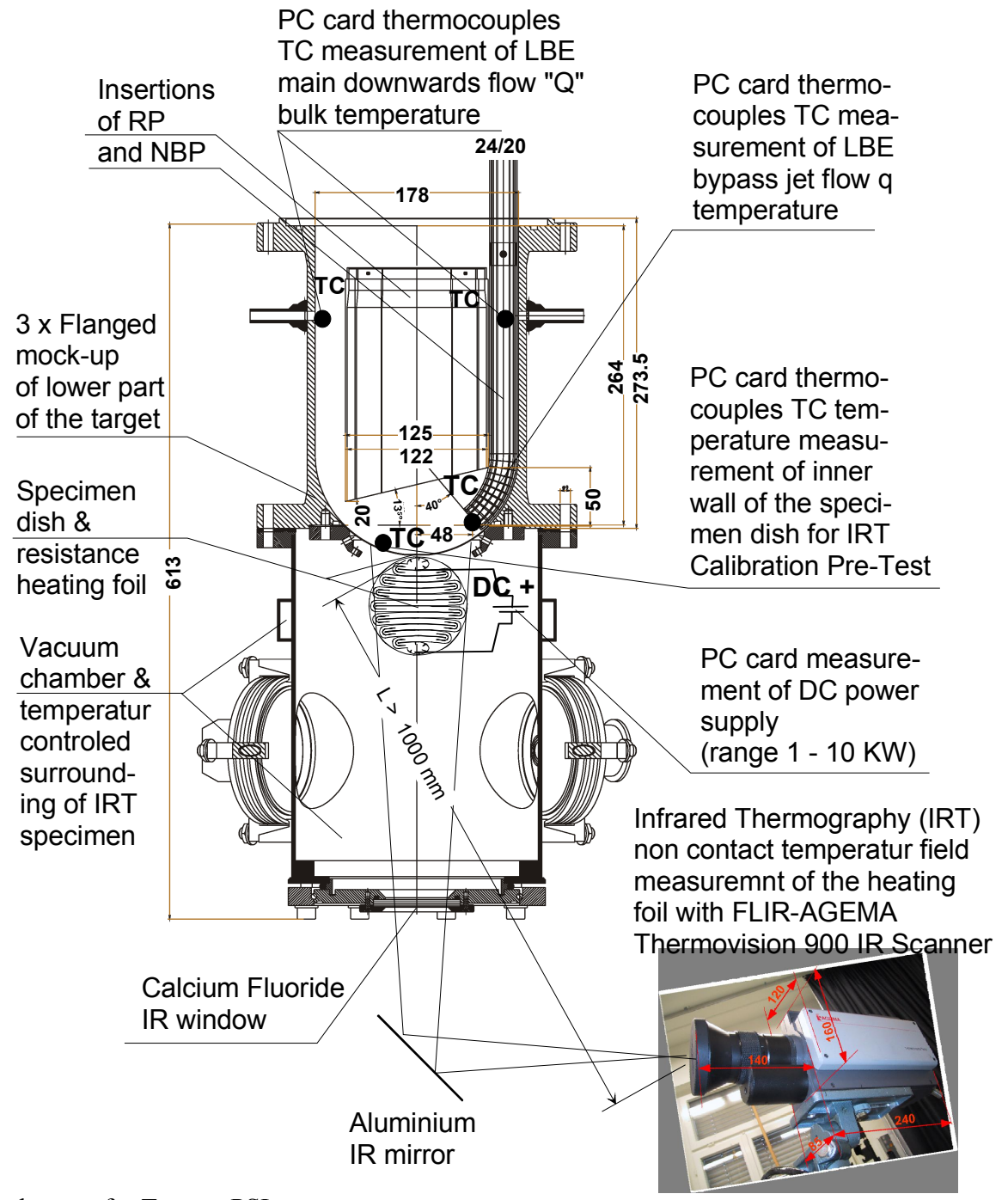

Figure 8. Experimental set up for Tests at PSI. 


\section{RESULTS}

\subsection{Electrical loading capacity of the HHF Sensors Dishes.}

In both series we have achieved approximately the maximum of planned DC load. For the HHF Sensor Dish \#4 the maximum has been achieved in the experiment series for the cooling with Main Flow of 1.5 1/s and By-pass "Jet" Flow of $0.3 \mathrm{l} / \mathrm{s}$. At the beginning for the voltage loads from $25-110 \mathrm{~V}$, we have observed the temperature range rising from 180 to $250^{\circ} \mathrm{C}$, and that the electrical resistance of sensor's heater was constant and amount ca. $4.3 \mathrm{Ohm}$. For higher loads up to $140 \mathrm{~V}$, the temperature arise over $250^{\circ} \mathrm{C}$ and the electrical resistance rose slightly up to $4.7 \mathrm{Ohm}$ for the average temperature of the sensor amount ca. $270^{\circ} \mathrm{C}$.For the DC Values applied: $129.6 \mathrm{~V}$ and $27.9 \mathrm{~A}$ with total power of $3626 \mathrm{~W}$ the heat flux has achieved the value of $62.7 \mathrm{~W} / \mathrm{cm}^{2}$ and $59.9 \mathrm{~W} / \mathrm{cm}^{2}$ calculating for the net and gross surface of the heater. By $139.5 \mathrm{~V}$ and 29.8A we have to stop the supplying of energy because mechanical contact problems, which has lead to burning through of the 28 microns thin heating layer occurred at net and gross heat fluxes of $72.1 \mathrm{~W} / \mathrm{cm}^{2}$ and

Table 5. Electrical loads of the HHF Sensor Dish \#04 for the thermo-hydraulics conditions of the series with Main Flow=1.5 1/s and By-pass Low Jet Flow $=0.21 / \mathrm{s}$

\begin{tabular}{|c|c|c|c|c|c|c|c|c|}
\hline \multicolumn{9}{|c|}{ Electr. and therm. loads of HHF sensor Dish \#04 during experiment series $D \# 4 M 15 B 02$, power supp. $B$} \\
\hline \multicolumn{4}{|c|}{ measured by homogenous distributed temperature; no by-pass jest, only main flow conditions } & & & \multirow{2}{*}{\multicolumn{2}{|c|}{$\begin{array}{l}\text { strip thickn. } t= \\
\text { strip length } L= \\
\end{array}$}} & \multirow{3}{*}{\begin{tabular}{|c|}
$0.028 \mathrm{~mm}$ \\
$466.95 \mathrm{~mm}$ \\
\\
Resistivity \\
ro= $\mathrm{R}^{*} \mathrm{t}^{\star} \mathrm{b} / \mathrm{L}$
\end{tabular}} \\
\hline$A$ net $=$ & 5780.90 & $m m^{\wedge} 2$ & & & \multirow{2}{*}{\begin{tabular}{|c|}
$1.00 \mathrm{~mm}$ \\
$12.38 \mathrm{~mm}$ \\
$\begin{array}{c}\text { heat flux } \\
\text { net }\end{array}$
\end{tabular}} & & & \\
\hline $\begin{array}{c}\text { nominal } \\
\text { load } \\
\text { Voltage }\end{array}$ & $\begin{array}{c}\text { measured } \\
\text { Voltage }\end{array}$ & $\begin{array}{c}\text { measured } \\
\text { Current }\end{array}$ & $\begin{array}{c}\text { measured } \\
\text { electr. } \\
\text { Resistance }\end{array}$ & $\begin{array}{c}\text { measured } \\
\text { Power }\end{array}$ & & $\begin{array}{c}\text { heat flux } \\
\text { gross }\end{array}$ & $\begin{array}{c}\text { sensors } \\
\text { wall } \\
\text { avg.Tem } \\
\text { perature }\end{array}$ & \\
\hline & [V] & {$[A]$} & & {$[W]$} & {$\left[\mathrm{W} / \mathrm{cm}^{\wedge} \mathbf{2}\right]$} & {$\left[\mathrm{W} / \mathrm{cm}^{\wedge} \mathbf{2}\right]$} & {$\left[{ }^{\circ} \mathrm{C}\right]$} & {$[\mathrm{Ohm} \cdot \mathrm{m}]$} \\
\hline 25 & 24.86 & 5.83 & 4.26 & 144.93 & 2.51 & 2.40 & 172.4 & $3.17 E-06$ \\
\hline 35 & 34.81 & 8.17 & 4.26 & 284.40 & 4.92 & 4.70 & 183.5 & $3.16 E-06$ \\
\hline 50 & 49.73 & 11.71 & 4.25 & 582.34 & 10.07 & 9.63 & 194.8 & $3.15 E-06$ \\
\hline 60 & 59.71 & 14.11 & 4.23 & 842.51 & 14.57 & 13.93 & 204.5 & $3.14 E-06$ \\
\hline 70 & 69.75 & 16.52 & 4.22 & 1152.27 & 19.93 & 19.06 & 215.1 & $3.13 E-06$ \\
\hline 80 & 79.66 & 18.90 & 4.21 & 1505.57 & 26.04 & 24.90 & 228.2 & $3.13 E-06$ \\
\hline 85 & 84.68 & 20.09 & 4.22 & 1701.22 & 29.43 & 28.14 & 234.8 & $3.13 E-06$ \\
\hline 90 & 89.60 & 21.33 & 4.20 & 1911.17 & 33.06 & 31.61 & 249.4 & $3.12 E-06$ \\
\hline $100^{*}$ & 92.11 & 21.91 & 4.20 & 2018.13 & 34.91 & 33.38 & 252.4 & $3.12 E-06$ \\
\hline
\end{tabular}

Table 6. Electrical loads of the HHF Sensor Dish \#01 for the thermo-hydraulics conditions of the series with Main Flow=1.0 1/s and By-pass Low Jet Flow $=0.11 / \mathrm{s}$

\begin{tabular}{|c|c|c|c|c|c|c|c|c|}
\hline \multicolumn{9}{|c|}{$\begin{array}{l}\text { Electr. and therm. loads of HHF sensor Dish \#01 during experiment series D\#1M10B01, power supp. A } \\
\text { measured by homogenous distributed temperature; no by-pass jest, only main flow conditions }\end{array}$} \\
\hline$A$ gross $=$ & 7137.59 & $m m^{\wedge} 2$ & \multicolumn{2}{|c|}{ gap breadth $g=$} & $1.00 \mathrm{~mm}$ & \multicolumn{2}{|c|}{ strip thickn. $t=$} & \multirow{3}{*}{\begin{tabular}{|r}
$0.06 \mathrm{~mm}$ \\
$963.84 \mathrm{~mm}$ \\
\\
Resistivity \\
ro= $=R^{*} t^{*} \mathrm{~b} / \mathrm{L}$
\end{tabular}} \\
\hline$A$ net $=$ & 6409.54 & $m m^{\wedge} 2$ & \multicolumn{2}{|c|}{ strip breadth $b=$} & $6.65 \mathrm{~mm}$ & \multicolumn{2}{|c|}{ strip length $L=$} & \\
\hline $\begin{array}{c}\text { nominal } \\
\text { load } \\
\text { Voltage }\end{array}$ & $\begin{array}{c}\text { measured } \\
\text { Voltage }\end{array}$ & $\begin{array}{c}\text { measured } \\
\text { Current }\end{array}$ & $\begin{array}{c}\text { measured } \\
\text { electr. } \\
\text { Resistance }\end{array}$ & $\begin{array}{c}\text { measured } \\
\text { Power }\end{array}$ & $\begin{array}{c}\text { heat flux } \\
\text { net }\end{array}$ & $\begin{array}{c}\text { heat flux } \\
\text { gross }\end{array}$ & $\begin{array}{c}\text { sensors } \\
\text { wall } \\
\text { avg.Tem } \\
\text { perature }\end{array}$ & \\
\hline & {$[V]$} & {$[A]$} & {$[\mathrm{Ohm}]$} & {$[W]$} & {$\left[W / \mathrm{cm}^{\wedge} 2\right]$} & {$\left[\mathrm{W} / \mathrm{cm}^{\wedge} 2\right]$} & {$\left[{ }^{\circ} \mathrm{C}\right]$} & {$[O \mathrm{Ohm} \cdot \mathrm{m}]$} \\
\hline 50 & 49.35 & 4.23 & 11.67 & 208.75 & 3.26 & 2.92 & 173.4 & $4.83 E-06$ \\
\hline 75 & 74.28 & 6.41 & 11.59 & 476.13 & 7.43 & 6.67 & 185.9 & $4.80 E-06$ \\
\hline 100 & 99.23 & 8.57 & 11.58 & 850.40 & 13.27 & 11.91 & 197.7 & $4.79 E-06$ \\
\hline 125 & 124.16 & 10.74 & 11.56 & 1333.48 & 20.80 & 18.68 & 212.6 & $4.79 E-06$ \\
\hline 150 & 149.04 & 12.93 & 11.53 & 1927.09 & 30.07 & 27.00 & 229.8 & 4.77E-06 \\
\hline 175 & 173.89 & 15.12 & 11.50 & 2629.22 & 41.02 & 36.84 & 250.1 & 4.76E-06 \\
\hline 200 & 198.91 & 17.35 & 11.46 & 3451.09 & 53.84 & 48.35 & 271.7 & 4.75E-06 \\
\hline 200 & 198.93 & 17.34 & 11.47 & 3449.45 & 53.82 & 48.33 & 274.7 & $4.75 E-06$ \\
\hline 225 & 218.96 & 19.12 & 11.45 & 4186.52 & 65.32 & 58.65 & 296.2 & $4.74 E-06$ \\
\hline 250 & 248.81 & 21.75 & 11.44 & 5411.62 & 84.43 & 75.82 & 326.6 & $4.74 E-06$ \\
\hline 275 & 273.60 & 23.92 & 11.44 & 6544.51 & 102.11 & 91.69 & 350.8 & $4.74 E-06$ \\
\hline 290 & 287.30 & 25.08 & 11.46 & 7205.48 & 112.42 & 100.95 & 369.1 & $4.74 E-06$ \\
\hline
\end{tabular}

$68.9 \mathrm{~W} / \mathrm{cm}^{2}$ respectively.

Table 5 shows results of sensor dish \#4 for another experiment series with Main Flow $=1.51 / \mathrm{s}$ and By-pass Low Jet Flow $=0.21 / \mathrm{s}$ : DC current values applied to the sensor Dish \#4 and average temperatures of the inner side of the dish achieving for the short phase of cooling by LBE with main flow only when the temperature was higher.

The absolute maximum of heat flux has been achieved during PSI-Test on the HHF Sensor Dish \#01 during series the series with Main Flow=1.0 1/s and By-pass Low Jet Flow $=0.1 \mathrm{l} / \mathrm{s}$. As documented in Table 6 by $287.3 \mathrm{~V}$ and $25.1 \mathrm{~A}$ we have operated the sensor with heat flux over $112 \mathrm{~W} / \mathrm{cm}^{2}$. It is up to now the highest heat flux, which we have achieved. All the time with stable resistivity and without problems in the meantime improved power supply wires contact.

Because have measured thickness of the sensor layers was very interesting to estimate the resistivity of plasma sprayed electrical conductors. The chemical composition of sprayed powder has created the electrical conductive layer, which had a constant resistivity over temperature. The constant electrical resistance of the sensors in different temperatures is causing the constant heat flux and allows determination of HTC-chart over cooled area using the 2DD-IRT methodology. The diagram in Fig. 9 shows this temperature independency behavior of sprayed heaters layers in comparison with others electrical conductors. 


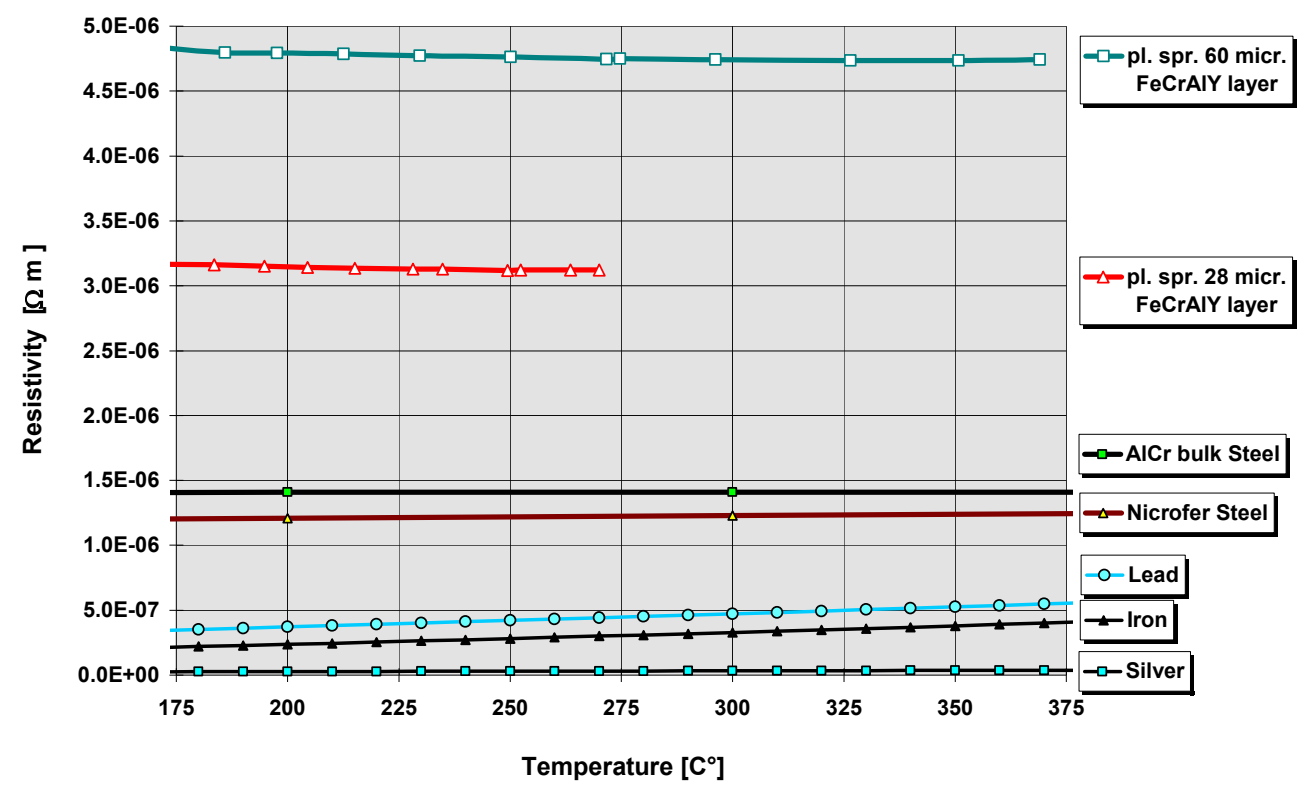

Figure 9. Important feature of sprayed sensor heater layers is experimentally determined high and temperature independent resistivity of both .

Even the earlier pre-test spraying trials have shown the weak bonding of the metallic on the ceramic layer. This bonding has been improved and we have achieved the stable connection HHF sensor dishes using our experience and try and goes procedure in many pre-tests trials spraying. Now after long electrical and thermal load, in both cases the adhesion between the layers and substrate was not damaged.

Even we have not observed the loosing of insulation. The earlier pre-test spraying trials have shown that the insulation ceramic spinel layer of the dish disappears once the metallic coating is applied. This problem has been solved by experimental try and go procedure with changing the LPPS-TF parameters The bonding of the metallic coating was successful but the cost was the increase of the el. resistance of the metallic circuit layer because of the thinner and rougher metallic coating.

\subsection{Heat transfer coefficient results from the Pre-Test for HHF Sensors Dishes.}

During evaluation of IRT data the correction of raw thermograms by using the individual emissivity for each measured pixel play important role. The rougher surface of the heater's layer has positive influence on the IRT measurements. The outer surface of the sensor heater's layer is very homogeny and has enough good emissivity, therefore can be measured by IRT technique without additional painting or other enhancement/improvement of emissivity. In Fig. 10 so called emissivity chart of the round foot print area of the HHF sensor dish \#04 showing very small differences of emissivity.

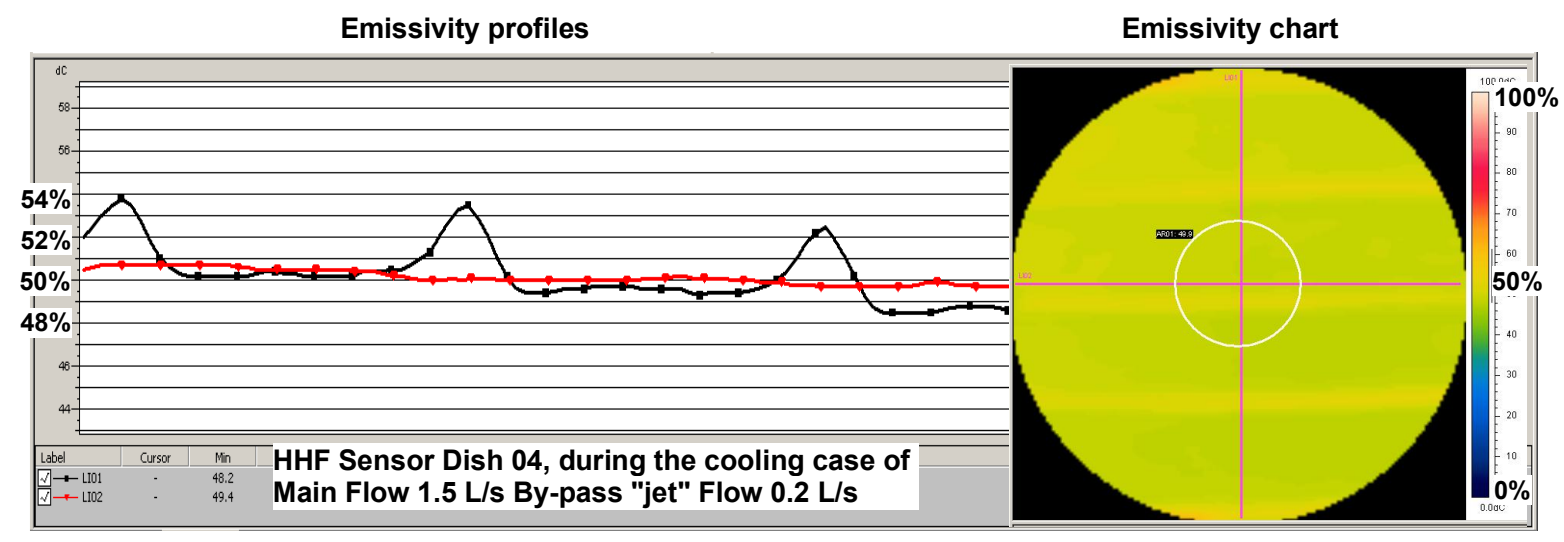

Figure 10. Emissivity chart for HHF Sensor Dish \#04 during experiment series 
For horizontal diameter line over the "foot print" area, the emissivity profile shows small changes within $1 \%$ only. On the vertical line emissivity profiles where it is periodical appearing of emissivity differences of $4 \%$ are caused through meander gaps between sections of heater. The emissivity of under laying ceramic spinnel in the small gap is little bit higher as the almost equal $50 \%$ emissivity of sprayed steel for the temperature level of ca. $180^{\circ} \mathrm{C}$.

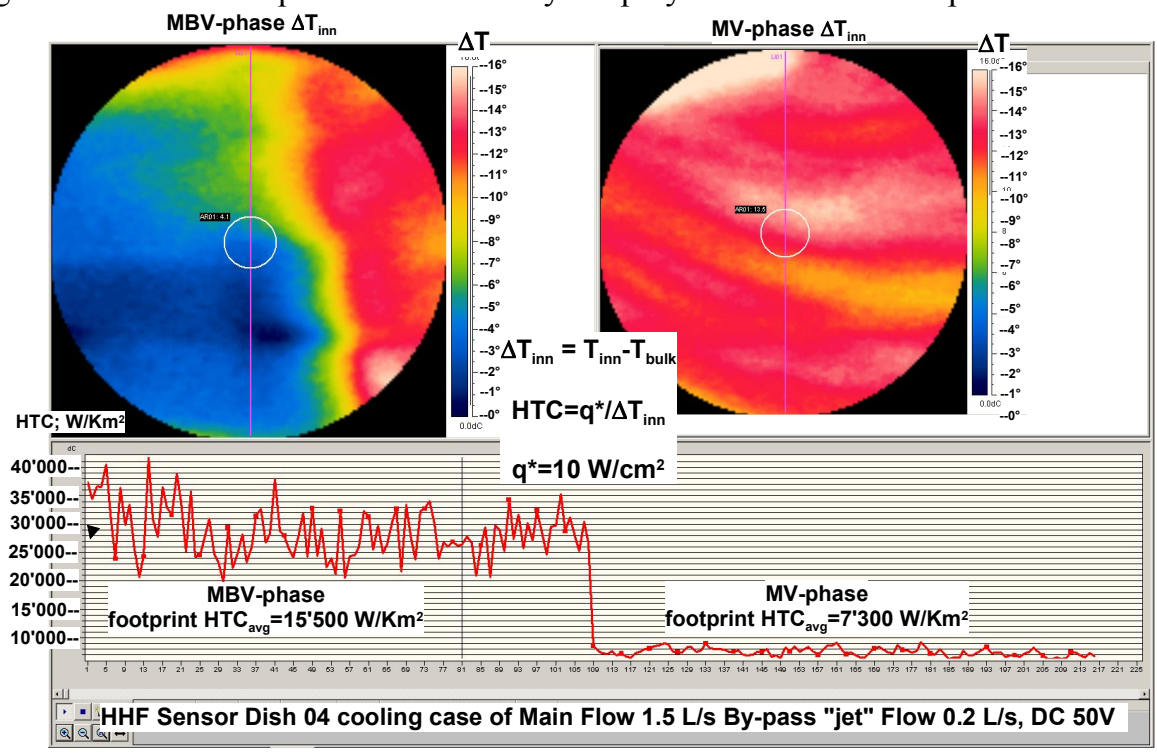

Figure 11: The $\Delta \mathrm{T}_{\mathrm{inn}}$ thermograms and HTC plots for PSI-Test of the HHF Sensor Dish \#04

Heat Flux Dependency of HTC measuerd with HHF Sensor Dish \#4 by constant LBE flow condition MF=1.5 I/s, BF=0.2 I/s

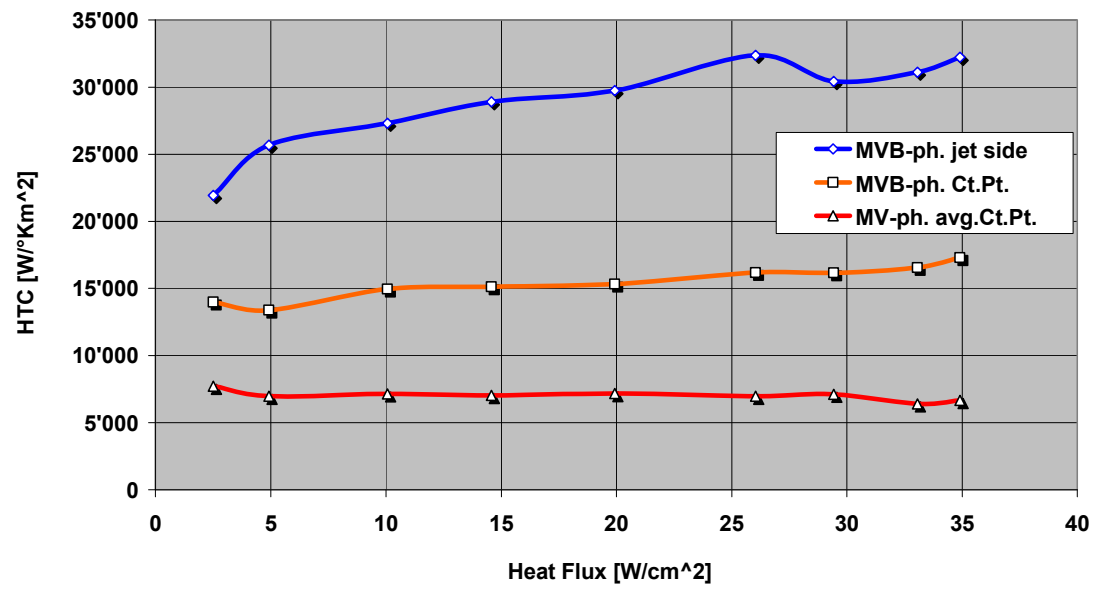

Figure 12: Influence of heat flux on HTC, measured at three points with HHF Sensor Dish \#04
In Fig.11 an example of cooling analysis, using the 2DD IRT methodology, is shown. With sequences of differential thermograms of inner surface temperature with LBE coolant bulk temperature $\Delta \mathrm{T}_{\mathrm{inn}}$, now obtain with stronger and reliable sensors, is possible to study the cooling by opaque coolants behind opaque walls for simulations of real high heat flux conditions. On the left differential thermogram under $50 \mathrm{~V}$ DC voltage $(\mathrm{V})$ the main $(\mathrm{M})$ and bypass (B) "jet" flows acting together in the MBV phase. The strong rotating main flow has pushed the jet streaming from his axis and sometimes the central area of the target is not sufficient good cooled. On the right differential thermogram for the MV-phase is shown, only the slowly rotating main flow is giving bigger $\Delta \mathrm{T}_{\mathrm{inn}}$ values. The simply arithmetic multiplication of heat flux applied to the sensor by the reciprocal field of $\Delta \mathrm{T}_{\mathrm{inn}}$ is resulting with HTC. In Fig 11 on the HTC time plot below both differential thermograms ca. two times lower cooling for the MV-phase can be observed.

The diagram in Fig. 12 shows another phenomenon, which can be analyzed with HHF sensors. For identical flow conditions within the series of with Main

Flow $=1.5$ 1/s and By-pass Low Jet Flow $=0.21 / \mathrm{s}$, during the MVB-phase, the measured HTC values are arising vs. heat flux. Because the higher velocity of the by-pass jet flows on the inner surface of the dish, the point placed closer to the jet outlet, shows this effect stronger as the central point area of the target window. The moderate increase of heat flux from 5 to $35 \mathrm{~W} / \mathrm{cm}^{2}$ brought for the jet side area the gain of HTC amount roughly $5500 \mathrm{~W} / \mathrm{Km}^{2}$, for the central point area it is $3500 \mathrm{~W} / \mathrm{Km}^{2}$ (from 13500 to $17000 \mathrm{~W} / \mathrm{Km}^{2}$ ). For the flow conditions without jet, during MV-phase and with lower velocities all over the whole "foot print" area, the HTC values are essentially lower and no effect of arising heat flux on the HTC values can be seen. 


\section{CONCLUSIONS}

With LPPS-TF technology, developed by Sulzer Metco Company in Switzerland, is possible to build HHF-sensors, which successfully fulfilling the specification needed for determination and visualizations of HTC connected with strong heated walls. The first tests performed at PSI in Switzerland have shown:

- on one hand; very promising results with the high heat flux of $112 \mathrm{~W} / \mathrm{cm}^{2}$, up to now, the record value for such type of sensor,

- on other hand; the power supply wiring contacts problem of this strong DC loaded active sensor.

The authors are working together for further improvement of this type of HHF sensors with the goal to achieve the planned heat flux maximum of $140 \mathrm{~W} / \mathrm{cm}^{2}$.

\section{ACKNOWLEDGEMENTS}

The authors wish to thank to the European Union EURATOM FP6 project VELLA (Virtual European Lead LAboratory) Dr. Gianluca Benamati http://192.107.58.30/index.html for the partially supporting this experimentation in scope of The Joint Research Activities (JRA) of VELLA.

http://cordis.europa.eu/fetch?CALLER=FP6 PROJ\&ACTION=D\&DOC=4\&CAT=PROJ\&QUERY=011 f50ddf9ff:ef3d:50f08e7e\&RCN=80059

Similarly the authors are grateful to the PT colleagues from PSI; especially to Filippo Barbagallo for the technical support during the preparation of the hardware and the operation of the PSI-LBE Double Loop and to Michael Wohlmuther for discussions during evaluation of experimental data and redaction of the paper.

\section{REFERENCES}

1. J.A. Patorski, F. Groeschel, "Experimental determination of local convection heat transfer coefficient field using two-dimensional and dynamic infrared thermography (2DD-IRT) method", Proceedings of SPIE, Thermosense XXVIII, Vol. 6205, (ISSN 0277-786X) , Jonathan J. Miles, G. Raymond Peacock, Kathryn M. Knettel, Editors, SPIE-, Bellingham, Washington 98227-0010 USA, 2006

2. J.A. Patorski, F. Groeschel: " Measurement of Heat Transfer Coefficient for a Proton Beam Entry Window of a Liquid Metal Target ", Journal of Heat Transfer Research, Volume 39, Number 7/2008, Pages 571-585, Copyright (C) Begell Haus, Inc. / The American Society of Mechanical Engineers, ISSN 1064-2285, Reddings, Connecticut 06896, USA (2008)

3. J.A. Patorski "Planning of the COOLWETT Experiment", International Workshop on Thermal-Hydraulics of Innovative Reactor and Transmutation Systems - THIRS, Forschungszentrum Karlsruhe, Germany, April 1416, 2008

4. D. Michels, J. Hadeler, J.H. Lienhard V, "High-Heat-Flux Resistance Heaters from VPS and HVOF Thermal Spraying“, Experimental Heat Transfer, Volume 11, Issue 4 , p. 341 - 359, Taylor \& Francis, UK, October 1998

5. A. Refke, G. Barbezat, J.L. Dorier, M.Gindrat, and Ch. Hollenstein, "Characterization of LPPS processes under various spray conditions for potential applications", Proceedings of the 4th ITSC, Orlando, Florida (2003), pp. $581 / 88$ 